\title{
Determination of hydraulic conductivity and shear strength properties of unsaturated residual soil from flysch rock mass
}

\author{
Josip Peranić ${ }^{1, *}$, Mariagiovanna Moscariello ${ }^{2}$, Sabatino Cuomo ${ }^{2}$, and Željko Arbanas ${ }^{1}$ \\ ${ }^{1}$ University of Rijeka, Faculty of Civil Engineering, Radmile Matejčić 3, 51000 Rijeka, Croatia \\ ${ }^{2}$ University of Salerno, Lab. Geotechnics, Department of Civil Engineering, Via Giovanni Paolo II, 132, 84084 Fisciano (SA), Italy
}

\begin{abstract}
Slopes in flysch deposits areas wide within Europe are highly prone to landslide occurrence. Depending on the material properties and climate conditions, instabilities in a form of earthflows, shallow and deep-seated landslides were observed in these formations. Typically, slope instabilities occurred after prolonged periods of rainfall. The Rječina River Valley, Croatia, built in flysch formation, is well known by several landslides occurred in the past. The weathering process of flysch rock mass and local climate conditions resulted in a specific engineering geological profile of the valley, with the unsaturated residual soil covering the bedrock. Although the behaviour of residual soil is important for a landslide triggering both through the rainfall infiltration process and (unsaturated) shear strength, hydro-mechanical properties of this material in unsaturated conditions were not investigated in the past. This paper summarizes the results of different laboratory tests performed on intact samples for hydro-mechanical characterization of the residual soil from flysch rock mass. It was found that the unique shear strength envelope could be used to determine failure conditions both for saturated and unsaturated conditions. The results obtained from strain-controlled and wetting tests performed in conventional and modified direct shear apparatuses indicated high values of the apparent cohesion that the near-surface soil can experience due to the increase of matric suction. The hysteresis effects and hydraulic paths to which soil was exposed to in the past were found to affect the soil behaviour, while the soil formation process results with a complex soil structure that imposes the necessity of using intact soil samples for proper hydraulic characterization of the soil.
\end{abstract}

\section{Introduction}

This paper presents some of the results of laboratory tests performed within a novel study that focuses on the role of the unsaturated zone in rainfall-induced landslides in flysch deposits [1]. While the effect of rainfall on the landslide triggering was investigated through the build-up of (positive) pore-water pressure along the sliding surface (e.g., [2-4]), very few studies have investigated the physical process of rainfall infiltration in a flysch slope (e.g., [5-7]) and how it affects the stability of flysch slope with time (e.g., [7]). Soil-water retention curve (SWRC) and the hydraulic conductivity function (HCF) are the unsaturated soil property functions required to analyse the transient process of rainfall infiltration. In order to determine how the redistribution of water content and change of matric suction affect the available shearing resistance along the (part of) sliding surface above the phreatic line, the functional relationship between the matric suction and shear strength has to be known. The latter can be related to the SWRC through effective stress (e.g., [8-10]).

Determination of unsaturated soil property functions involves the usage of expensive laboratory devices that enable control or measurement of (matric) suction during a test. Change of volume of a tested specimen due to change of matric suction, maintenance of the hydraulic contact, air diffusion and cavitation of water are some of the commonly encountered problems when performing laboratory or field measurements in partially-saturated soils (e.g., [11,12]). Test duration is another challenge when determining unsaturated soil properties experimentally. This especially refers to fine-grained soils, where low hydraulic conductivity further reduces under increasing soil suction conditions. Thus, aside from the need for covering a wide range of matric suction that fine-grained soil can typically exhibit, the above-mentioned problems are even more pronounced due to prolonged testing time.

To overcome these shortcomings, various estimation methods for the prediction of unsaturated soil properties were developed. For example, grain-size distribution or basic index soil properties can be used to predict SWRC (e.g., $[13,14])$. Regression-based approaches can be used to determine HCF based on observed flow quantities (e.g., [15]). Another common approach is to estimate the HCF from the SWRC and some other soil properties (e.g., $[16,17])$. SWRC can be used to predict the unsaturated shear strength as well (e.g., [18, 19]).

In this study, the hydraulic conductivity and shear strength properties were determined experimentally on intact samples of residual soil from flysch rock mass. 
Firstly, the saturated hydraulic conductivity $\left(k_{s}\right)$ was determined on intact and remoulded samples using the outflow tests performed in conventional oedometer and triaxial apparatuses. Measurements collected on intact samples tested in the HYPROP device and the extended evaporation method [20] were used to obtain the HCF in a considered range of matric suction. Finally, the HCF was estimated from the SWRC and $k_{s}$. Series of straincontrolled direct shear tests were performed in saturated conditions, both on intact and remoulded samples. Suction-controlled and wetting tests were performed on intact samples by using the modified, axis-translation based direct shear apparatuses (DSA). The obtained data were used to define a unique shear strength envelope in terms of the Bishop's effective stress formulation. Some general conclusions on hydro-mechanical properties of the investigated soil are outlined in the end.

\section{Investigation area and soil characterization}

In recent years, persistent rainfall has triggered several landslides in the Rječina River Valley, Croatia. The last larger landslide occurred in February 2016, at the SW slope of the valley above the Valići Lake [21]. This landslide was chosen as a pilot area for the new comprehensive study that investigates the importance of unsaturated zone for rainfall-induced landslides in flysch slopes. The superficial samples of the residual soil, taken from different parts of the Valići landslide body, showed that the material covering the slope has similar features in terms of the grain-size distribution and Atterberg's limits, and could be classified as lean clay (CL) [22]. Intact samples were collected from the sampling pit located in the central part of the Valici landslide. Handdrilled samples, collected from the soil surface up to a few meters of depth, were used to determine soil density, natural water content, and basic soil index properties (Table 1). Several details of specimen collection are outlined in Fig. 1.

The formation process of the residual soil covering slopes of the valley results with the specific soil structure, characterized by the occasional presence of macro voids and siltstone grains that can vary in size and weathering degree. Measurements for determination of the SWRC showed that different SWRC is obtained when remoulded and consolidated samples are used instead of intact ones [22]. Best-fit SWRC parameters of intact soil are summarized in Table 2.

\section{Experimental procedures}

Measurements for the determination of hydraulic conductivity and shear strength properties in saturated conditions were performed on both intact and remoulded samples. As it was found that $k_{s}$ values for intact and remoulded samples differ significantly, all measurements for determination of unsaturated soil properties were performed on intact samples. Thus, the obtained unsaturated soil properties of the residual soil from flysch rock mass are representative for in situ soil.

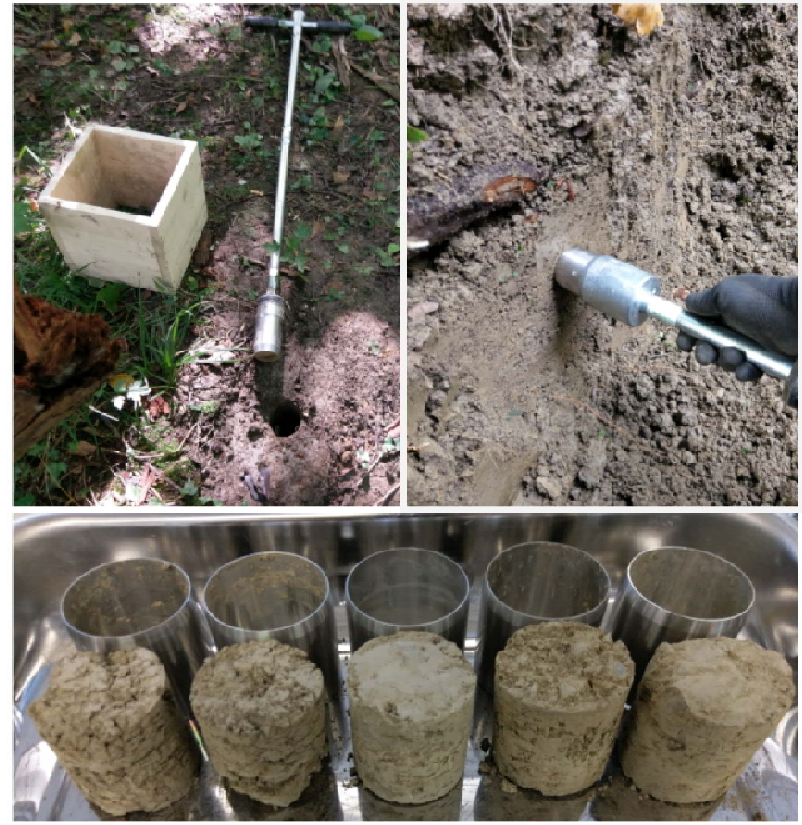

Fig. 1. Some details about the collection of intact near-surface samples for determination of $w_{n}$ and basic soil properties.

Table 1. Basic soil properties of the investigated soil (CL).

\begin{tabular}{|c|c|c|c|c|c|c|}
\hline \multirow[b]{2}{*}{$\begin{array}{l}G_{S} \\
(/)\end{array}$} & \multirow[b]{2}{*}{$\begin{array}{r}\gamma_{S} \\
\left(\mathrm{kNm}^{-3}\right)\end{array}$} & \multicolumn{3}{|c|}{ Grain size distrib. } & \multicolumn{2}{|c|}{ Plast. limi. } \\
\hline & & $\begin{array}{r}\mathrm{C} \\
(\%) \\
\end{array}$ & $\begin{array}{r}\mathrm{M} \\
(\%)\end{array}$ & $\begin{array}{r}\mathrm{S}+\mathrm{G} \\
(\%)\end{array}$ & $\begin{array}{l}w_{L} \\
(\%)\end{array}$ & $\begin{array}{l}w_{P} \\
(\%)\end{array}$ \\
\hline 2.7 & 20.9 & 30.3 & 53 & 16.7 & 44 & 24 \\
\hline
\end{tabular}

Table 2. The van Genuchten best-fit SWRC parameters [22].

\begin{tabular}{lrrrrr}
\hline & $\begin{array}{r}\theta_{\mathrm{s}} \\
\left(\mathrm{m}^{3} / \mathrm{m}^{3}\right)\end{array}$ & $\begin{array}{r}\theta_{r} \\
\left(\mathrm{~m}^{3} / \mathrm{m}^{3}\right)\end{array}$ & $\begin{array}{r}\alpha \\
\left(\mathrm{kPa}^{-1}\right)\end{array}$ & $\begin{array}{r}n \\
(/)\end{array}$ & $\begin{array}{r}m \\
(/)\end{array}$ \\
\hline $\begin{array}{l}\text { Drying } \\
\text { process }\end{array}$ & 0.463 & 0.028 & 0.004 & 1.186 & 0.323 \\
\hline $\begin{array}{l}\text { Wetting } \\
\text { process }\end{array}$ & 0.335 & 0.011 & 0.005 & 0.973 & 0.348 \\
\hline$\alpha, n, m=$ const.; $\theta_{\mathrm{s}} \& \theta_{\mathrm{r}}=$ saturated \& residual volumetric \\
water content
\end{tabular}

\subsection{Hydraulic conductivity tests}

Until this research, the hydraulic conductivity features of the residual soil that covers the slopes of the Rječina River Valley were completely unknown. Falling and constant head test methods (ASTM D5084-03) were used to determine $k_{s}$ of intact and remoulded specimens under different confining pressures. Hydraulic conductivity in unsaturated conditions was determined using the extended evaporation method.

\subsubsection{Measurements of $k_{s}$}

Falling head measurements were performed in conventional, front-loading oedometer apparatus 26WF0320 (Controls S.p.A). Specimens were submerged into de-aired water, while the change of the water level in the burette through time was used to calculate $k_{s}$ 
values. Constant head measurements were performed in conventional triaxial apparatus 28-WF4050 (Controls S.p.A). Saturation of the tested specimens was achieved by incremental back-pressurization until $\mathrm{B}$ value $\geq 0.95$ was measured. Outflow tests were performed on cylindrical specimens with a diameter/length of $38 / 72$ mm. Fig. 4 shows intact and remoulded specimens used for the determination of $k_{s}$ with the falling head method.

\subsubsection{Measurements of $k_{w}$}

The intact cylindrical specimens of diameter/height dimensions $80 / 50 \mathrm{~mm}$ were installed in the HYPROP device (HYdraulic PROPerty analyzer) to define the HCF within a limited range of matric suction. Three intact specimens were tested, starting from (i) natural water content $\left(\mathrm{HYP}_{\mathrm{wn}}\right)$; (ii) saturated prior to testing by immersion into the water with $\left(\mathrm{HYP}_{1}\right)$; and, without the application of a small vacuum $\left(\mathrm{HYP}_{2}\right)$. Water loss due to evaporation recorded by the precise scale and matric suction readings from two mini-tensiometers were used to calculate the coefficient of permeability respective to water phase $k_{w}$ according to the Darcy-Buckingham law:

$$
k_{\mathrm{w}}\left(\psi_{\text {mean }}\right)=\Delta m\left(\alpha A \varphi_{w} \Delta t i_{m}\right)
$$

where $\psi_{\text {mean }}$ is the mean tension averaged over a time interval of $\Delta t_{i}, \Delta m$ sample mass difference in $\Delta t_{i}$ recorded by the scale $(\mathrm{g}), \varphi_{w}$ density of water, $a$ flux factor depending on the soil type, $A$ cross-section area of the specimen $\left(\mathrm{cm}^{2}\right)$, and $\Delta i_{m}$ average hydraulic gradient [23].

Table 3 presents the water content, degree of saturation and the void ratio for each specimen before and after saturation. The HYPROP (UMS GmbH) device used in the study is shown in Fig. 5.

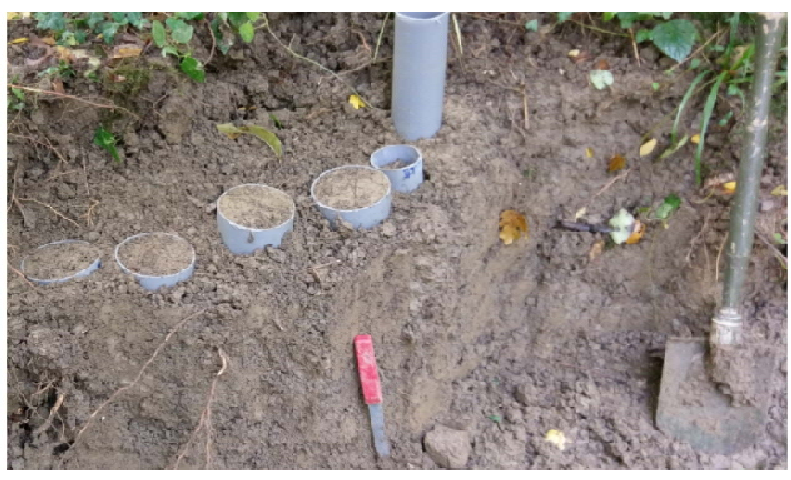

Fig. 2. Collection of intact samples in the sampling pit.

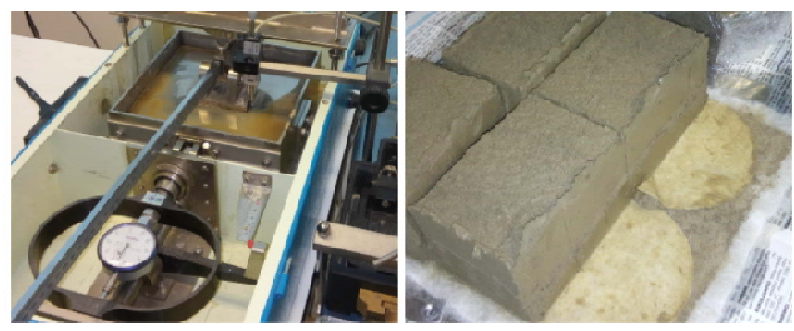

Fig. 3. Preparation of completely remoulded and consolidated samples used for $k_{s}$ determination (photos taken by D. Božoki).

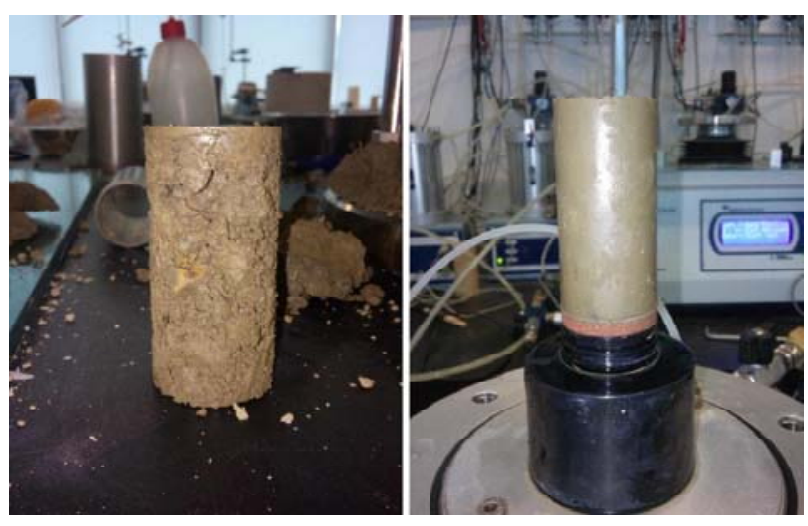

Fig. 4. Intact (left) and remoulded specimen (right) used for $k_{s}$ determination (photos taken by D. Božoki).

Table 3. Characteristics of intact specimens tested in the HYPROP device.

\begin{tabular}{lrrrrr}
\hline & \multicolumn{2}{c}{ At natural wat. cont. } & \multicolumn{2}{r}{ Initial (saturated) } \\
\hline \multirow{2}{*}{ Specimen } & $\begin{array}{r}e \\
{[/]}\end{array}$ & $\begin{array}{r}S \\
{[\%]}\end{array}$ & {$[\%]$} & $\begin{array}{r}w_{i} \\
{[\%]}\end{array}$ & $\begin{array}{r}S_{i} \\
{[\%]}\end{array}$ \\
\hline $\mathrm{HYP}_{\mathrm{wn}}$ & 0.86 & 25.0 & 78.0 & 24.7 & 77.0 \\
\hline $\mathrm{HYP}_{1}$ & 0.73 & 20.8 & 76.0 & 25.3 & 93.0 \\
\hline $\mathrm{HYP}_{2}$ & 0.75 & 23.2 & 83.0 & 27.8 & 100.0 \\
\hline
\end{tabular}

$e=$ void ratio; $w=$ water content; $S=$ degree of saturation

\subsection{Shear strength tests}

Conventional DSA was used to determine shear strength properties of intact and remoulded samples in saturated conditions, while two axis-translation based DSAs were used to investigate shear strength properties of intact samples in unsaturated conditions.

\subsubsection{Shear tests in saturated conditions}

Strain-controlled tests were performed on intact specimens using the conventional DSA 27-WF2160 (Controls S.p.A.). After the installation into the shear box at preserved $w_{n}$, specimens were submerged into deaired water and consolidated under 50,100 , or $200 \mathrm{kPa}$ of vertical stress. Following the consolidation stage, specimens were sheared at the rate of $5 \mathrm{E}-03 \mathrm{~mm} / \mathrm{min}$ : When the maximal shear displacement was reached, material from each testing device was collected separately, thoroughly mixed with distilled water and left to rest overnight. The same amount of material was

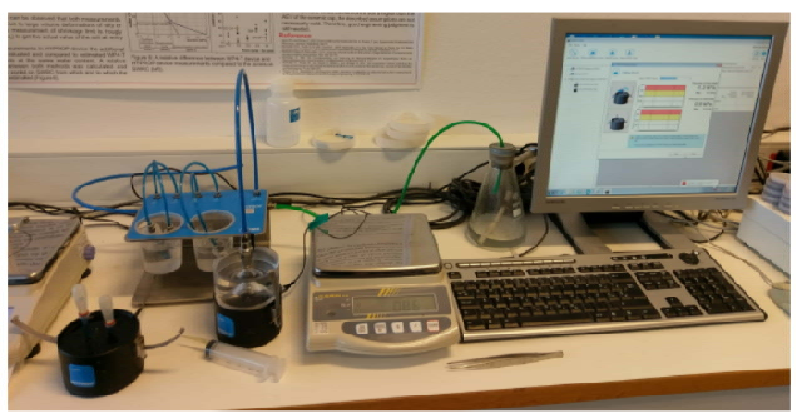

Fig. 5. HYPROP device (UMS GmbH) at the UniLj (see [22]). 
installed in the same testing device, and an identical testing procedure was repeated on the produced specimens as it was in a case for the intact ones. The adopted testing program was aimed to identify possible differences in shear strength properties only due to specimen disturbance effects. Fig. 6 outlines several details about testing with conventional DSA.

\subsubsection{Shear tests in unsaturated conditions}

Unsaturated shear strength properties were determined on intact specimens using two axis-translation based DS apparatuses. The Suction Controlled Direct Shear Apparatus (SCDSA) (Megaris s.a.s.) was used to perform three suction controlled tests starting from the $w_{n}$. Specimens were consolidated under 50, 100 and 200 $\mathrm{kPa}$ of the net vertical stress, equilibrated at $36 \mathrm{kPa}$ of matric suction and sheared at the same rate of 5E-03 $\mathrm{mm} / \mathrm{min}$. The unsaturated version of the Back Pressured Shear Box (GDS Instruments Ltd.) was used to perform suction-controlled and wetting tests on intact samples. Specimens were saturated prior to installation in the shear box by submerging into de-aired water or installed at the $w_{n}$. Standard (strain-controlled) tests were performed at a shear rate of $5 \mathrm{E}-03 \mathrm{~mm} / \mathrm{min}$, under different matric suction and net vertical stress values. Additionally, two wetting tests were performed on relatively dry intact specimens collected during the summer period. After installation into the shear box with a closed drainage valve, matric suction values, corresponding to the $w_{n}$, of 350 and $400 \mathrm{kPa}$ were measured. Normal and shear stress conditions were applied and, once the deformations have ceased, the long-lasting wetting stage was started. Under imposed $\sigma_{\text {net }} / \tau$ stress conditions, matric suction was decreased, causing the increase of specimens water content until the acceleration of shear displacements (i.e. failure conditions) were observed. More details about wetting tests could be found in [24]. Two axis-translation based DSAs used in the study are shown in Fig. 7.

\section{Results and discussion}

The obtained results indicate that, as it was the case with SWRCs [22], saturated hydraulic conductivity of residual soil from flysch rock mass differs greatly if measured on remoulded instead of intact samples (Fig. 8 ). For a similar void ratio, $k_{s}$ measured for remoulded
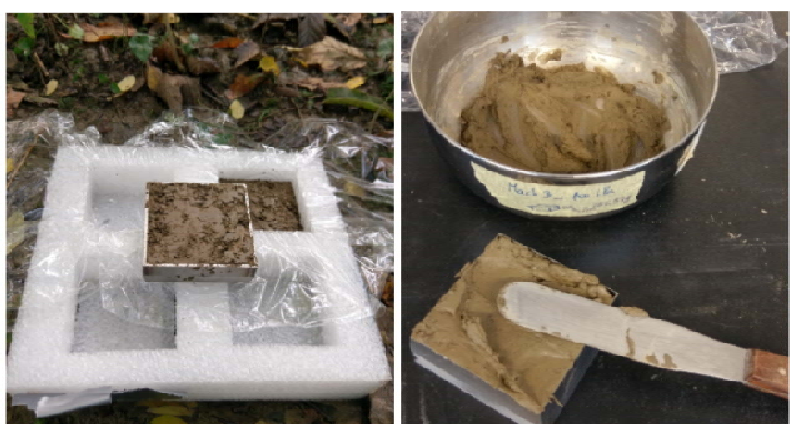

Fig. 6. Collection of intact samples (left) and preparation of remoulded specimen (right) for testing with conventional DSA.

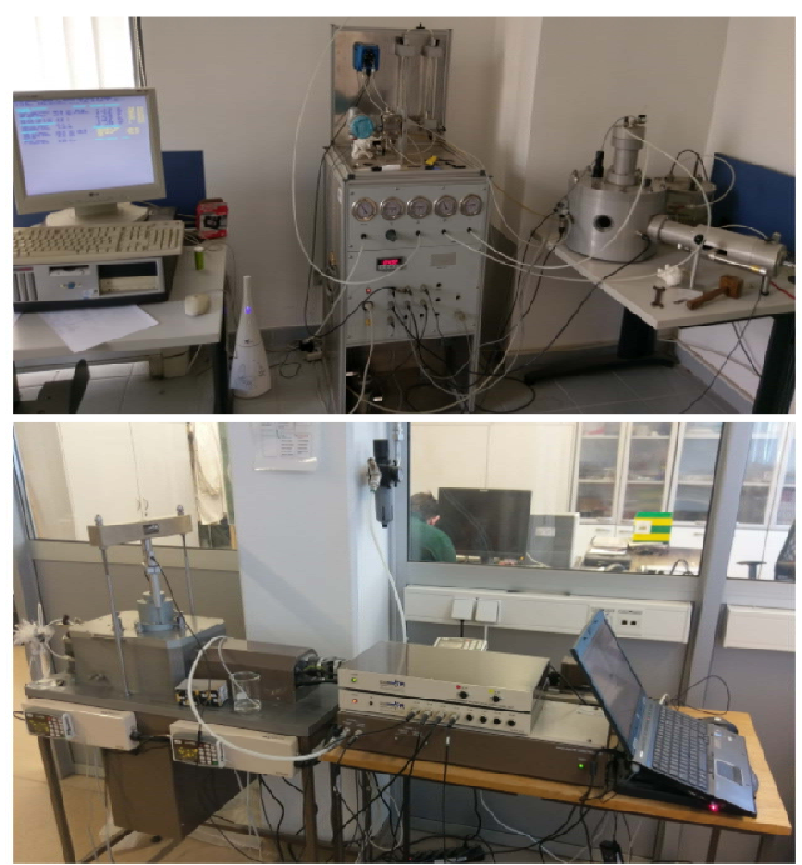

Fig. 7. Suction-controlled DS apparatuses at the UniSa (Megaris s.a.s.) (top), and UniRi (GDS Inst. Ltd.) (bottom).

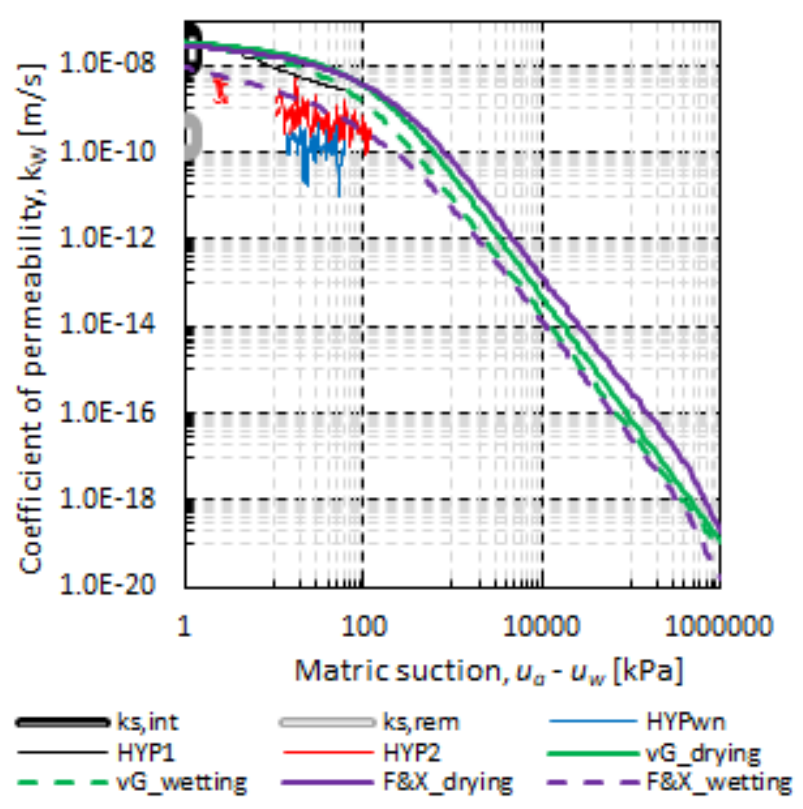

Fig. 8. Measured $k_{s}$ and $k_{w}\left(u_{a}-u_{w}\right)$ values determined on intact samples with HYPROP device and HCF estimated from the eq. (2) and (3).

samples was approx. two orders of magnitude lower than for intact ones. As expected, measurements with the HYPROP device indicated a decrease of $k_{w}$ with an increase of matric suction, while higher $k_{w}$ values were obtained for specimens saturated prior to testing. For vacuum-saturated specimen and low matric suction values, $k_{w}$ and $k_{s}$ match closely. Finally, $k_{s}$ and SWRC parameters determined on intact samples [22] were used to estimate the HCF representative for the investigated soil, according to the equations proposed by van Genuchten [25] and Fredlund et al. [26]:

$$
k_{w}(\psi)=k_{s} \frac{\left\{1-(\alpha \psi)^{n-1}\left[1+(\alpha \psi)^{n}\right]^{-m}\right\}^{2}}{\left[1+(\alpha \psi)^{n}\right]^{0.5}}
$$




$$
k_{w}(\psi)=k_{s} \frac{\int_{\ln (\psi)}^{b} \frac{\theta\left(e^{y}\right)-\theta(\psi)}{e^{y}} \theta^{\prime}\left(e^{y}\right) d y}{\int_{\ln \left(\psi_{A E V}\right)}^{b} \frac{\theta\left(e^{y}\right)-\theta_{s}}{e^{y}} \theta^{\prime}\left(e^{y}\right) d y}
$$

where $\alpha, n$, and $m$ are constant, $e^{y}$ is a natural number raised to the dummy variable power, and $\theta^{\prime}$ is the derivative of the Fredlund and Xing's SWRC equation.

Unlike for the hydraulic conductivity, the difference in saturated shear strength test results obtained for intact and remoulded samples was not that significant (Fig. 9). Fig. 10 represents the behaviour of intact specimens sheared in saturated and unsaturated conditions. The obtained results indicate that, for the same confining pressure, increasing matric suction results in an increase of shear strength, while compressive behaviour during shearing in saturated or nearly saturated conditions, changes to dilative with an increase of matric suction. The threshold value of matric suction separating two patterns of behaviour was found to increase with the increasing of the $\sigma_{\text {net }}$. Conditions at failure obtained for saturated and suction-controlled tests are presented along with the stress paths from two wetting tests in Fig. 11.

The effective stress was calculated according to the formulation proposed by Bishop

$$
\sigma^{\prime}=\left(\sigma-u_{a}\right)+\chi\left(u_{a}-u_{w}\right)
$$

with an effective stress parameter assumed to be equal to the current degree of saturation $(\chi=S)[8,27]$.

Disregarding the confining pressure, all saturated specimens exhibited a contractive behaviour. The volumetric behaviour of unsaturated specimens was affected by both the net vertical stress and suction applied during the shearing. The peak shear strength parameters were estimated for saturated conditions on intact $\left(c^{\prime}=5 \mathrm{kPa}, \phi=31.7^{\circ}\right)$ and remoulded samples $\left(c^{\prime}=6 \mathrm{kPa}, \phi=28.6^{\circ}\right)$. The results obtained on intact samples indicate that the evaluation of the effective stress as proposed by Bishop (4) yields a unique set of shear strength parameters $\left(c^{\prime}=5 \mathrm{kPa}, \phi=31.7^{\circ}\right)$ both for saturated and unsaturated conditions (Fig. 11). The latter is more suitable to be compared with the stress conditions of intact samples undergoing the wetting process. Stress paths of the two wetting tests shown in Fig. 11 reveal that the failure upon wetting is reached only when the stress path approached the obtained failure envelope.

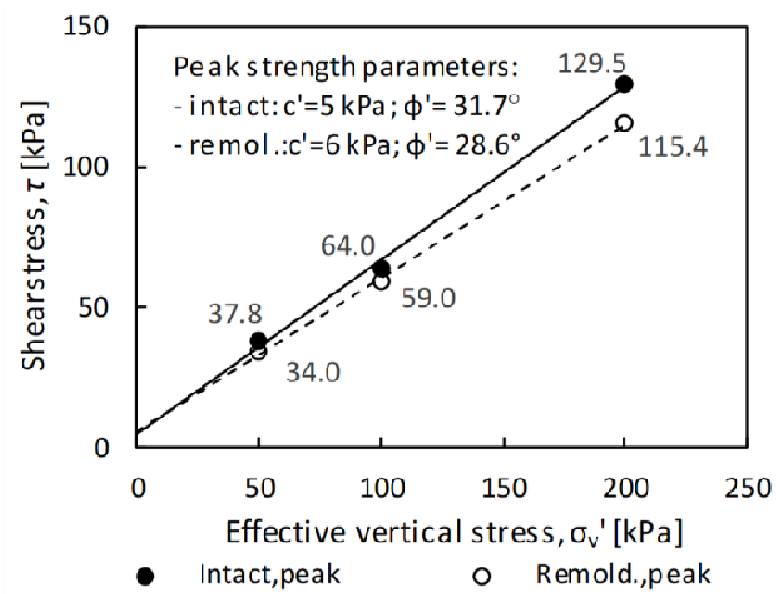

Fig. 9. Peak shear strength envelopes for intact and remoulded specimens tested in saturated conditions.
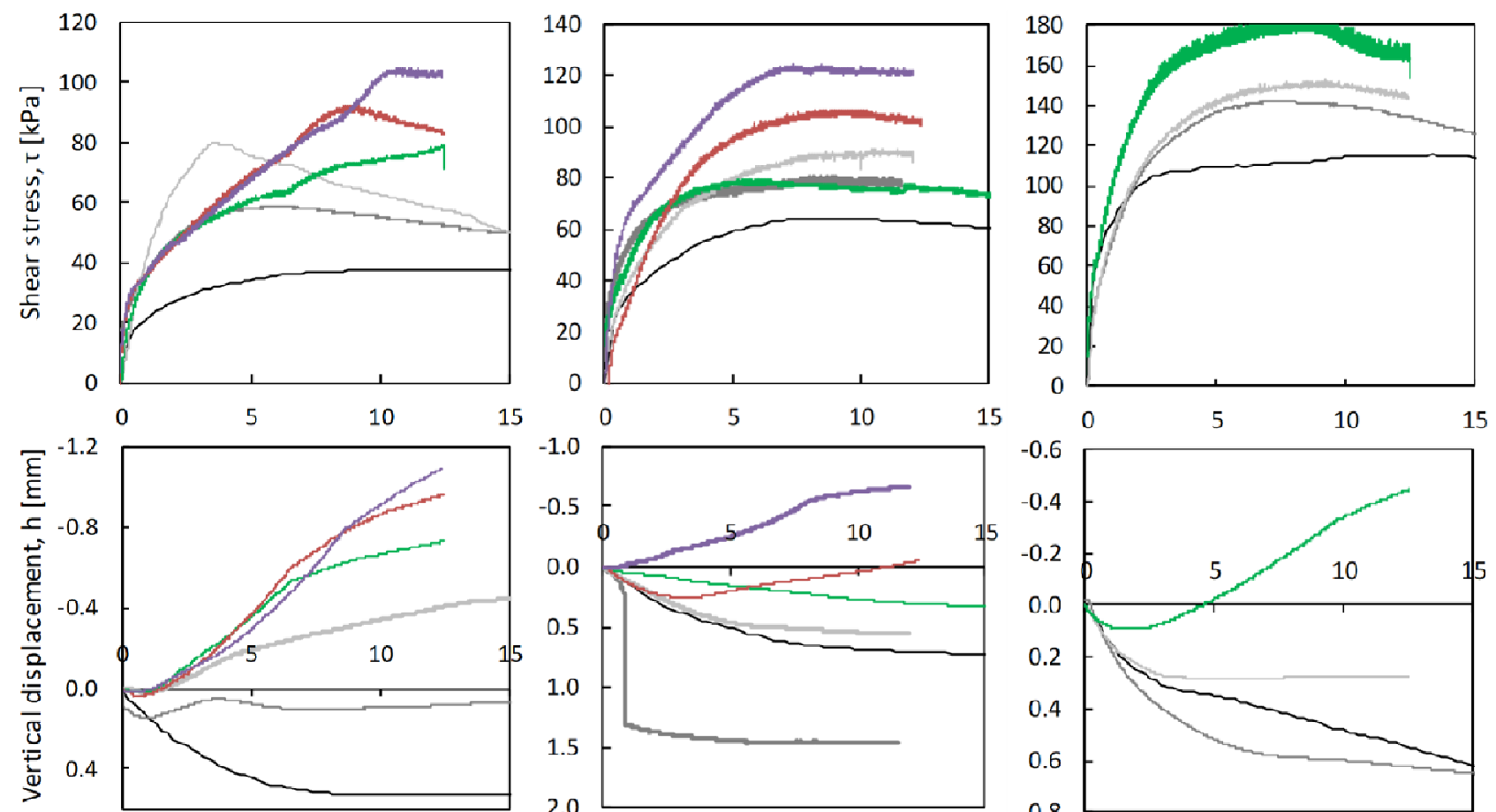

Hori zontal displacement, $\mathrm{d}_{\mathrm{h}}[\mathrm{mm}]$
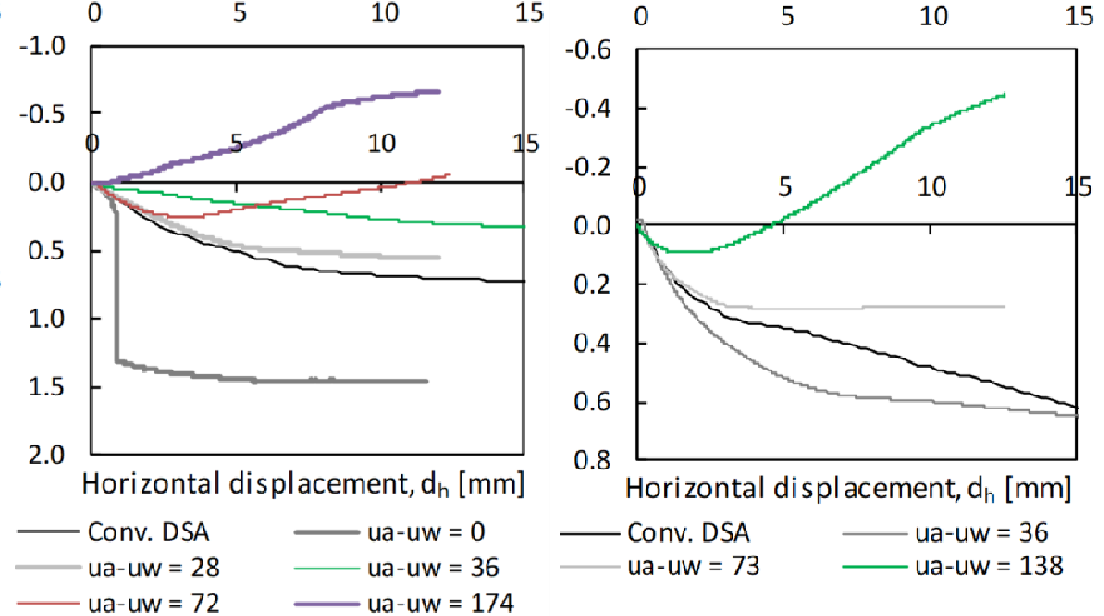

Fig. 10. Shearing stage test results obtained on intact samples under 50 (left), 100 (middle), and $200 \mathrm{kPa}$ (right) of net vertical stress. 


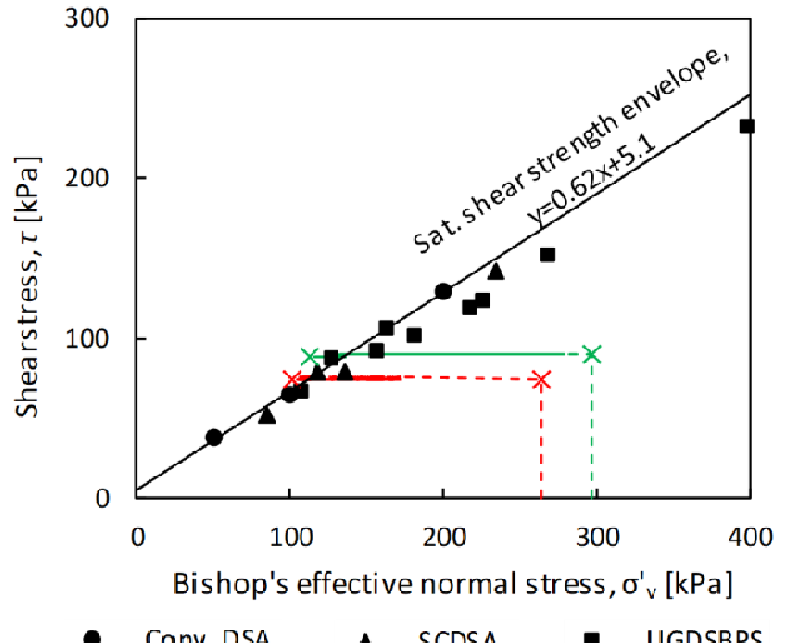

Fig. 11. A unique shear strength envelope [8] with stress paths from two wetting tests (modified from [24]).

\section{Conclusions}

Some of the test results for the hydro-mechanical characterization of residual soil form flysch rock mass are presented in this manuscript. The obtained results suggest that soil formation process and hydraulic paths to which the soil was exposed in its history results with a need for using intact samples to correctly define its hydro-mechanical properties. For a considered range of matric suction, measured $k_{w}$ was found to correspond with the estimated HCF for intact samples. A unique set of shear strength parameters was obtained by using the effective stress formulation proposed by Bishop (4) both for saturated and unsaturated conditions. The same shear strength envelope was found to be able to predict stress conditions at failure in case of wetting tests as well. In all cases, an increase of matric suction caused increasing of shear strength, and change from contractive to dilative soil behaviour.

The obtained results will be important for further researches of rainfall-induced landslides in flysch deposits. The obtained soil properties are particularly useful for investigation of the rainfall infiltration process and landslide triggering, especially in case of the smallscale physical model of flysch slope, where the shear strength component associated with the matric suction may represent a dominant part of the available (total) shear strength along the sliding surface.

\section{Acknowledgements}

The research presented in this paper was supported by Croatian Science Foundation under the Project IP-2018-01-1503 Physical modelling of landslide remediation constructions behaviour under static and seismic actions (ModLandRemSS). This support is gratefully acknowledged. The part of laboratory equipment used for laboratory testing was provided in the frame of Project "Research Infrastructure for Campus based Laboratories at the University of Rijeka", co-funded in part by the Ministry of Science, Education and Sports of the Republic of Croatia and the European Fund for Regional Development (ERDF).

\section{References}

1. J. Peranić Dissertation Importance of geotechnical cross-section unsaturated zone for landslide occurrence in flysch deposits (2019)

2. M. Prodan, S. Dugonjić Jovančević, Ž. Arbanas, Proc. of the 1st ReSyLAB, 85-90 (2013)

3. Ž. Arbanas, S. Mihalić Arbanas, M. Vivoda Prodan, J. Peranić, M. Sečanj, S. Bernat Gazibara, M. Krkač, Proc. of the, WLF2017, 649-657 (2017)

4. M. Berti, L. Bertello, A.R. Bernardi, G. Caputo, Landslides, 14, 6 (2017)

5. M. Berti, A. Simoni, Hydrol. Process., 26 (2012)

6. M. Maček, B. Majes, A. Petkovšek, RIG, 50 (2016)

7. J. Peranić, V. Jagodnik, Ž. Arbanas, Proc. of the XVII ECSMGE (2019)

8. A. Bishop, Teknisk Ukeblad, 106, 39 (1959)

9. N. Lu, J.W. Godt, D.T. Wu, Water Resour Res, 46 (2010)

10. R. Greco, R. Gragano, Water Resour Res, 51 (2015)

11. F.A.M. Marinho, W.A. Take, A. Tarantino, Geotech Geol. Eng, 26 (2008)

12. D.G. Fredlund, S.L. Houston, Advances in Unsaturated Solis-PanAmUNSAT, 15-31 (2013)

13. Y. Perera, C. Zapata, W. Houston, S. Houston, Geot. Spec. Publ. 130-142 GRI-18, 49-60 (2005)

14. M.H. Mohammadi, M. Vanclooster, Vadose Zone Journal, 10 (2011)

15. M. Nakhaei, J. Šimunek, Jour of Hydrol and Hydrom, 25, 1 (2014)

16. Q. Zhai, H. Rahardjo, Eng. Geol., 199, 14 (2015)

17. A. Rahimi, H. Rahardjo, E. Leong, Soils and Foundations, 55, 6 (2015)

18. S.K. Vanapalli, D.G. Fredlund, D.E: Pufahl, A.W. Clifron, Can. Geotech. J., 33 (1996)

19. Q. Zhai, H. Rahardjo, A. Satyanaga, G. Dai, Acta Geotechnica, (2019)

20. U. Schindler, Arch. Acker- Pflanzenbau Bodenkd, 24 (1980)

21. S. Mihalić Arbanas, M. Sečanj, S. Bernat Gazibara, M. Krkač, Ž. Arbanas, Proc. of the 2nd ReSyLAB, 197-202 (2017)

22. J. Peranić, Ž. Arbanas, S. Cuomo, M. Maček, Geofluids, ID 6297819 (2018)

23. U. Schindler, G. von Unold, W. Durner, L. Muller, ICEACE'2015, 47-52 (2015)

24. J. Peranić, Ž. Arbanas, Bulletin of Engineering Geology and the Environment (in press).

25. M.T. van Genuchten, Soil Science Society of America Journal, 44, 5 (1980)

26. D.G. Fredlund, A. Xing, S. Huang, Canadian Geotechnical Journal, 31, 4 (1994)

27. N. Lu, W. Likos, J. Geotech. Geoenviron. Eng., 133, 2 (2006) 